\title{
State anxiety modulates the return of fear
}

\author{
Manuel Kuhn M.Sc. ${ }^{a^{*}}$, Gaetan Mertens M.Sc. ${ }^{b^{*}} \&$ Tina B. Lonsdorf Ph.D. ${ }^{a}$ \\ ${ }^{a}$ Department of Systems Neuroscience, University Medical Center Hamburg-Eppendorf, \\ Hamburg, Germany \\ ${ }^{\mathrm{b}}$ Ghent University, Ghent, Belgium \\ * These authors contributed equally
}

\section{Corresponding author:}

Tina B. Lonsdorf, University Medical Center Hamburg-Eppendorf, Department of Systems Neuroscience, Martinistr. 52, 20251 Hamburg, Germany, t.lonsdorf@uke.de, tel.: +49 40741057868 , fax: +49 40741059955 


\section{ABSTRACT}

Current treatments for anxiety disorders are effective but limited by the high frequency of clinical relapse. Processes underlying relapse are thought to be experimentally modeled in fear conditioning experiments with return fear (ROF) inductions. Thereby reinstatementinduced ROF might be considered a model to study mechanisms underlying adversity-induced relapse. Previous studies have reported differential ROF (i.e. specific for the danger stimulus) but also generalized ROF (i.e. for safe and danger stimuli), but reasons for these divergent findings are not clear yet. Hence, the response pattern (i.e. differential or generalized) following reinstatement may be of importance for the prediction of risk or resilience for ROF. The aim of this study was to investigate state anxiety as a potential individual difference factor contributing to differentiability or generalization of return of fear.

Thirty-six participants underwent instructed fear expression, extinction and ROF induction through reinstatement while physiological (skin conductance response, fear potentiated startle) and subjective measures of fear and US expectancy were acquired. Our data show that, as expected, high state anxious individuals show deficits in SCR discrimination between dangerous and safe cues after reinstatement induced ROF (i.e. generalization) as compared to low state anxious individuals.

The ability to maintain discrimination under aversive circumstances is negatively associated with pathological anxiety and predictive of resilient responding while excessive generalization is a hallmark of anxiety disorders. Therefore, we suggest that experimentally induced ROF might prove useful in predicting relapse risk in clinical settings and might have implications for possible interventions for relapse prevention.

KEYWORDS anxiety, reinstatement, return of fear, mood induction, fear generalization 


\section{INTRODUCTION}

Anxiety and stress-related disorders are highly prevalent and tend to be persistent (Wittchen et al., 2011). A major limitation to long-term remission of anxiety disorders is the high relapse rate despite of effective psychological and pharmacological interventions (Yonkers, Bruce, Dyck, \& Keller, 2003). Thus, relapse prevention may represent a good intervention point for improving long-term therapeutic efficacy, which has recently become a major focus of experimental and clinical research (Fitzgerald, Seemann, \& Maren, 2014; Haaker et al., 2013; Kindt, Soeter, \& Vervliet, 2009; Schiller et al., 2010).

Processes underlying clinical relapse are modeled in the laboratory using classical conditioning paradigms and return of fear (ROF) manipulations following extinction training in animals and humans (Bouton, 2002; Vervliet, Craske, \& Hermans, 2013). Thereby, extinction is thought to generate competing inhibitory extinction memories that co-exist with fear memories (Bouton, 2004; Myers \& Davis, 2007) rather than erase them. Insufficient expression of extinction memories upon re-confrontation with the conditioned stimulus at a later time thus results in ROF (Bouton, 2002), a suggested experimental analog of clinical relapse (Vervliet et al., 2013). Experimentally, ROF can be induced by the mere passage of time (spontaneous recovery), a contextual change (renewal) and the unexpected re-exposure to the unconditioned stimulus or another aversive event (reinstatement, RI) (Bouton, 2004; Vervliet et al., 2013).

Reinstatement has been well characterized in rodent single-cue studies (i.e. employing only one conditioned stimulus) already decades ago (Bouton \& Bolles, 1979; Bouton, 2000; Rescorla \& Heth, 1975). In humans however, differential conditioning protocols (i.e. employing a safe conditioned stimulus [CS-] and a conditioned danger stimulus [CS+]) yield evidence for reinstatement-induced ROF specifically (or more pronounced) to the CS+ (differential reinstatement) in some studies, while others demonstrate ROF to both CS+ and 
CS- to a similar degree (generalized reinstatement) (Haaker, Golkar, Hermans, \& Lonsdorf, 2014). Of note, single cue designs, as employed in rodents, do not allow for a dissociation between generalized or differential increase of ROF.

Importantly, the ability to maintain discrimination under aversive circumstances is negatively associated with pathological anxiety (Duits et al., 2015; Lissek et al., 2005) and predictive of resilient responding to stress (Craske et al., 2012). Furthermore, excessive generalization (i.e., failure to discriminate dangerous from safe stimuli) is a common hallmark of anxiety disorders (Duits et al., 2015; Lissek et al., 2005). Hence, the response pattern (i.e. differential or generalized) following experimental reinstatement may prove useful for the prediction of risk of clinical relapse or resilience (Haaker et al., 2014; Scharfenort \& Lonsdorf, 2016). Accordingly, it has been suggested that reinstatement-induced ROF may serve as an experimental model for studying mechanisms underlying adversity-induced clinical relapse (Scharfenort, Menz, \& Lonsdorf, 2016) although clinical studies are lacking to date.

Individual differences in the ability to acquire and extinguish conditioned fear have already been identified by prior research (Haaker et al., 2015; Indovina, Robbins, Núñez-Elizalde, Dunn, \& Bishop, 2011; Kindt \& Soeter, 2014). The contribution of individual differences to the quality (i.e. CS discrimination) of ROF remain however largely unexplored to date. Thereby, state anxiety represents a particularly strong candidate, as a number of preliminary reports have linked trait anxiety and exposure to life adversity to the quality of ROF following reinstatement. In particular, different studies from Merel Kindt's lab (Kindt et al., 2009; Kindt \& Soeter, 2013; Soeter \& Kindt, 2010) suggest that reinstatement to the CSresponse may be correlated with trait anxiety manifesting however only in SCRs (Kindt \& Soeter, 2013; Soeter \& Kindt, 2010) or only in FPS (Kindt et al., 2009) in different studies. In addition, accounting for trait anxiety as a covariate changed SCRs results from generalized to differential reinstatement effects in one report (Kindt \& Soeter, 2013) but the direction of this finding was not further discussed. Furthermore, this effect was only observed in some 
experimental groups across studies (Kindt et al., 2009; Soeter \& Kindt, 2010).

Hence, these inconclusive effects across studies and dependent measures may suggest that trait anxiety, as a stable individual tendency to respond with an increase in state anxiety in face of adversity (Spielberger, Gorsuch, Lushene, Vagg, \& Jacobs, 1983), may not show a uniform link to return of fear phenomena. In fact, state anxiety (i.e. the unpleasant response while coping with adverse situations (Spielberger et al., 1983)), may also exert a direct effect on the quality of ROF as state-trait models (of anxiety) assume that the impact of traits on responding and behavior are mediated by states (Spielberger et al., 1983). Hence, state anxiety might be more directly linked to emotional processing and may thus exert a more uniform effect on behavior than traits, although both are conceptually interrelated.

Recently, a preliminary study suggested a link between high state anxiety and CS discrimination in fear-potentiated startle during ROF to contextual stimuli (GlotzbachSchoon, Andreatta, Mühlberger, \& Pauli, 2015), but studies on cued conditioning are lacking to date. The purpose of the present study was hence to investigate an association between state anxiety and reinstatement-induced ROF to cued CSs in a larger sample. Thereby we employed a multimodal investigation of this phenomenon by using subjective ratings of fear and expectancy of the unconditioned stimulus (US) as well as different physiological measures (SCRs, FPS) which have been suggested to be reflective of different underlying mechanisms of fear learning and expression (Hamm \& Weike, 2005; Lipp \& Purkis, 2005; Lipp, 2006). For instance, SCRs can be considered an index of arousal whereas FPS have been shown to closely follow stimulus valence (Hamm \& Weike, 2005; Lipp \& Purkis, 2005; for in-depth discussion see Lipp, 2006).

Based on our previous results (Scharfenort \& Lonsdorf, 2016) we expected individuals characterized by high state anxiety to display less discriminative (i.e. generalized) responding following adversity-induced ROF in the laboratory (i.e. reinstatement), which is expected to be primarily driven by increased CS- responding. 


\section{MATERIALS AND METHODS}

Participants. Forty-four right-handed volunteers were recruited via advertisements at a local online job offer platform for students. Eight subjects were excluded [technical issues $(\mathrm{N}=3)$, insufficient belief in instructions $(\mathrm{N}=4)$, failure to induce an aversive US $(\mathrm{N}=1)$ ] leaving 36 participants (21 females; mean age/s.d.: 27 years/4.9) for analyses. The study was approved by the General Medical Council Hamburg and volunteers were paid 20 Euro. The study was conducted in accordance with the Declaration of Helsinki.

Prior to the experiment, participants provided written informed consent and completed the State version of the State-Trait Anxiety Inventory in German (STAI-S; Spielberger, Gorsuch, Lushene, Vagg, \& Jacobs, 1983). Main effects of task of this study have been reported elsewhere (Mertens et al., 2015) and data were re-analyzed here by means of a dimensional approach to study the role of state anxiety. To integrate our results into the existing literature employing a categorical approach (e.g. Glotzbach-Schoon et al., 2015; Scharfenort et al., 2016), significant findings were followed up by exploratory analyses, categorically grouping participants into high and low STAI state anxious groups based on a median split (see Supplementary Materials).

\subsection{Experimental stimuli.}

Stimulus presentation was controlled with Presentation software (NeuroBehavioral Systems, Albany California, USA). Blue snow fractals (200 by 200 pixels) in a white square presented in the center of a black background (Mertens et al., 2015) served as CSs (duration 8s) and a white fixation cross on a black background served as the inter-trial-interval (ITI, duration 13, 15 or $17 \mathrm{~s}$ ). The US was an electro-tactile stimulus (three $2 \mathrm{~ms}$ rectangular pulses; inter-pulse interval $40 \mathrm{~ms}$ ) administered to the back of the right hand with a $1 \mathrm{~cm}$ diameter surface electrode with a platinum pin (Specialty Developments, Bexley, UK) through a Digitimer 
DS7A constant current stimulator (Hertfordshire, UK).

\subsection{Procedure}

The procedure has been published in detail previously as a report of the main effect of task ${ }^{1}$ and will thus only be briefly described in the following (Mertens et al., 2015). Prior to the experiment, participants underwent a calibration procedure to individually adjust US intensity. The first experimental phase functioned as a fear expression phase in which participants were informed by a cover story (for the purpose of studying the role of experience vs. instruction referred to as training phase), that only one of the CSs (that is, the CS1) but never the CS- would be followed by the US (coinciding with CS offset). A third CS (CS2) served the purpose of investigating the role of instruction on fear expression (Mertens et al., 2015) and participants were instucted that the CS2 would be followed by the US during test but not training while in fact no US was presented during the test phase. The second experimental phase served as an extinction phase (for the purpose of the cover story labeled test phase) and consisted of non-reinforced presentations of all CSs, even though participants were informed that CS1 and CS2 would be reinforced.

Fear expression and extinction consisted of 27 trials (9 per CS type) per experimental phase, whereof the CS1 was reinforced twice during expression only as previous work has shown that actual CS-US pairing experience adds little to an instructed fear conditioning design (Mertens et al., 2015; Raes, De Houwer, De Schryver, Brass, \& Kalisch, 2014). In between the extinction and the reinstatement test (reinstatement-test) phase, three unannounced reinstatement USs (ISI of $5 \mathrm{~s}$ ) were delivered (37 s after the last CS onset during extinction, that is $5 \mathrm{~s}$ after the end of the last rating block during extinction and $5 \mathrm{~s}$ after reinstatement context onset). The reinstatement context consisted of a black background (i.e. the cue

\footnotetext{
${ }^{1}$ due to space restrictions, these interesting results could not be included in this first manuscript in particular as the focus of our previous (main effect of task, fear expression) and the current paper (individual differences) are different.
} 
background to maintain the experimental context (Haaker et al., 2014)) and avoid context switches. Seventeen s after the last reinstatement US, the first of nine (three of each CS type) additional unreinforced CS presentations during the reinstatement-test phase was presented (CS type counterbalanced).

During $2 / 3$ of the CS presentations (for each CS type), a startle probe was administered (5.5s or $6.5 \mathrm{~s}$ post-CS onset). The first CS after the reinstatement USs was always startled to capture the transient reinstatement effect. During the ITI, startle probes were administered in $2 / 3$ of the cases $(5 / 6 / 8 / 9 \mathrm{~s}$ for the $13 \mathrm{~s}$ ITI; $5 / 6.5 / 9.5 / 11 \mathrm{~s}$ for the $15 \mathrm{~s} \mathrm{ITI} ; 5 / 7.5 / 11 / 13$ for the $17 \mathrm{~s}$ ITI).

\subsection{Psychophysiological recordings and subjective ratings}

Skin conductance (SCR) and startle signals were recorded (Mertens et al., 2015) using a BIOPAC MP-100 amplifier and Acqknowledge 3.9 software (BIOPAC Systems Inc, Goleta, California, USA). Data were manually scored offline using a custom-made program according to published recommendations (Blumenthal et al., 2005; Boucsein et al., 2012). Reactions showing recording artifacts (i.e. electrode malfunctioning) or when spontaneous blinks occurred right before (i.e. 50ms), during or right after the startle probe onset (for startle reactions only) were treated as missing data points (Mertens et al., 2015). Briefly, SCRs were scored as the first response initiating within a 0.9-4.0 s post-CS/US onset with a minimumamplitude $>0.02 \mu \mathrm{S}$. Prior to analysis, SCR data (magnitude) were log-transformed and range -corrected. Startle responding was elicited using a $95 \mathrm{~dB}$ white noise burst presented binaurally through Sennheiser headphones (Wedemark, Germany). The raw signal was rectified and integrated. Startle responses occurring 20-120ms post-startle-probe onset were scored (Blumenthal et al., 2005). Prior to analysis, startle data (magnitudes) were Ttransformed. One participant was excluded from analyses of startle data due to insufficient data quality.

US expectancy and fear ratings (referring to the most recent encounter for each CS) were 
provided every nine trials on 9-point Likert scales (Mertens et al., 2015).

\subsection{Statistical analyses}

Data were analyzed using SPSS 22 for Windows (IBM Corp., Armonk, NewYork). AMOS (Version 22) was used to construct path analyses testing the direct effects of STAI-S on CS1/CS- and CS2/CS- discrimination before and after reinstatement on multiple read-out measures. Due to the transient effect of reinstatement, blocks of three single trials (Haaker et al., 2014; Scharfenort \& Lonsdorf, 2016) per time-point were employed for SCRs and blocks of 2 single trials for startle (note that only $2 / 3$ of trials were startled). As subjective ratings were only provided intermittently, single-rating trials were used for analyses. Importantly, the relevance of a varying number of trials in statistical analyses of reinstatement effects has been discussed in our recent review (Haaker et al., 2014) and experimentally investigated in our recent publication demonstrating that results are strongest when considering single-trials but comparable when considering blocks of two or three single trials (Scharfenort \& Lonsdorf, 2016).

Path analyses as an extension of multiple regression allows to estimate the magnitude and significance on the hypothesized causal effect state anxiety exerts on ROF- induced reactivity for each outcome measure and, additionally, determines the associative relationship between all dependent variables in one comprehensive model. Starting from a saturated model including data of all dependent variables as well as age and sex and allowing all possible connections, backward selection of non-significant paths (trends up to $\mathrm{p}<0.01$ were included) was performed. Starting from this initial model, non-significant paths were removed from the final model. Significant effects of STAI-S on any dependent measure were followed up by reduced path analyses for each dependent variable testing CS1/CS- and CS2/CSdiscrimination before and after reinstatement as well as CS-specific changes in responding from before to after reinstatement. Paths testing for a possible influence of age and sex were 
also added to these analyses.

In addition, to test for a possible impact of state anxiety on mean conditioned responding during fear expression (i.e. practice phase) and extinction (i.e. test phase) similar path models were constructed for these experimental phases. Level of significance was set at $\mathrm{p}<0.05$, twosided model fit was assessed using root mean square error of approximation (RMSEA) with thresholds of $<0.01,<0.05,<0.08,<0.10$ and $>0.10$ indicating excellent, good, fair, mediocre or poor fit of the final model (Browne \& Cudeck, 1992; MacCallum, Browne, \& Sugawara, 1996). Reported regression coefficients reflect standardized betas.

\section{RESULTS}

We refer to our previous work (Mertens et al., 2015) for a detailed description of the main effects of task. Briefly, results of this study showed that instructions elicited robust fear expression with only a marginally additional impact of actual CS-US pairing experience. Importantly, non-differential ROF was observed independently from actual experience or fear instruction on all dependent measures.

\subsection{The impact of state anxiety on CS discrimination during fear expression and extinction}

In line with our main hypothesis that state anxiety primarily affects the responding in face of adversity (i.e. reinstatement manipulation), no significant impact of state anxiety on fear expression and extinction has been observed for any of the dependent variables. In detail, neither path analyses for fear expression (practice) and extinction (test) revealed any significant impact of STAI-S on difference scores between CS1/CS- and CS2/CS- (data not shown).

All path analyses revealed a significant impact of age on STAI-S scores (standardized path coefficient: $0.34, \mathrm{p}=0.032$ ) indicating decreased state anxiety with increasing age. 


\subsection{The impact of state anxiety on CS discrimination during return of fear}

In line with our hypothesis, state anxiety showed a significant negative association (Figure 1) with reinstatement induced differential responding between CS1 and CS- for SCRs (standardized path coefficient: $-0.34 ; \mathrm{p}=0.030$ ) as well as between CS2 and CS- for FPS (standardized path coefficient: $-0.45 ; \mathrm{p}=0.001$ ). The final model showed a good model fit indicated by RMSEA=0.033.

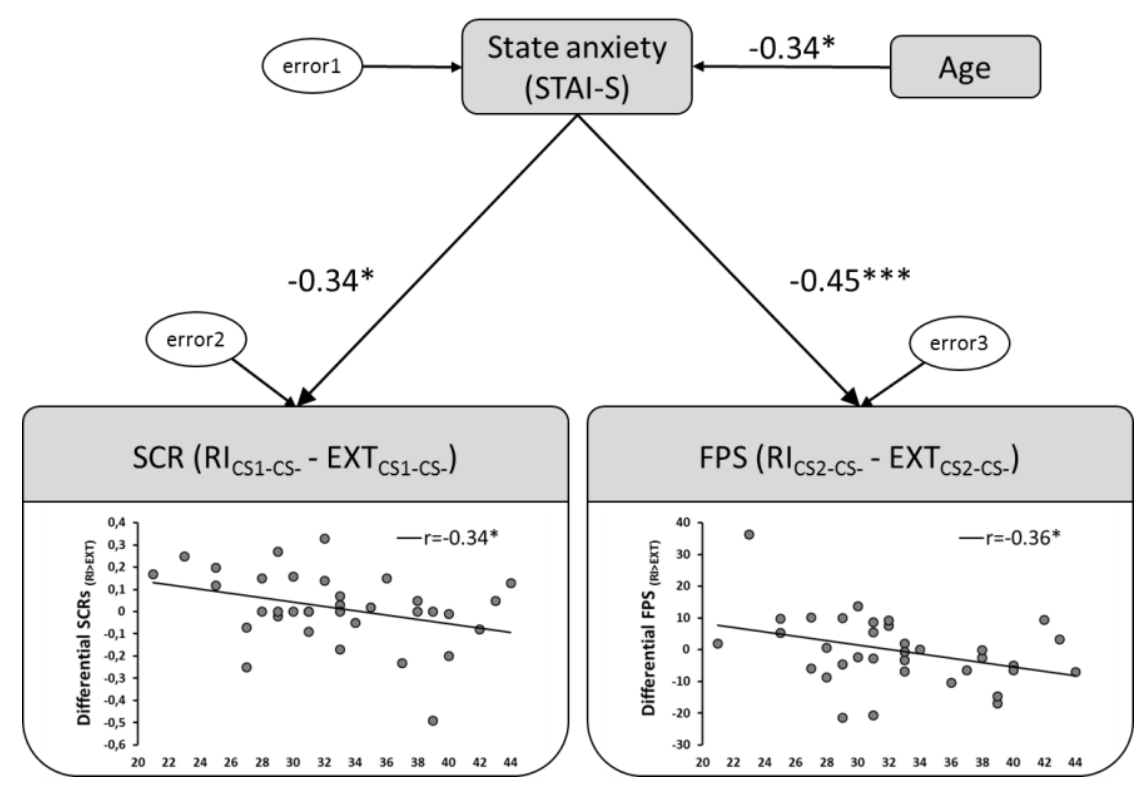

Figure 1. Path diagram depicting the reduced final model after backward selection of non-significant paths showing a negative association of state anxiety (STAI-S) with reinstatement-induced responding between CS1 and CS- for SCRs as well as between CS2 and CS- for FPS including corresponding scatterplots

Note that paths not included in the figure were non-significant (i.e. backward-selection).

For SCRs, this effect resulted from a significant influence of STAI-S on CS1/CSdiscrimination after (standardized path coefficient after reinstatement: $-0.40, \mathrm{p}=0.003$, model fit RMSEA<0.001, Supplementary Materials Figure S1) but not before reinstatement induction (no significant path). More precisely, higher state anxiety scores were associated with lower CS1/CS- discrimination after reinstatement. In addition, state anxiety did not impact on response enhancement to the CS1 or the CS- specifically (no significant paths). Hence, the effect results from genuine CS discrimination that can neither be specifically 
attributed to enhanced CS1 responding or reduced CS- responding from the end of extinction to the post-reinstatement test phase.

For FPS, only CS2 response enhancement from the end of extinction to post-reinstatement test was negatively associated with state anxiety (standardized path coefficient: -0.42 , $\mathrm{p}=0.005$, model fit RMSEA $<0.001$, Supplementary Materials Figure S2). More precisely, lower anxiety scores were associated with stronger response enhancement to the CS2 from before to after reinstatement. Furthermore, no impact of state anxiety on CS- response enhancement (no significant path) or timepoint-specific (before or after reinstatement manipulation) CS2/CS- discrimination was observed (no significant paths).

In contrast to SCRs and FPS, no significant effects were observed for reinstatement-induced response enhancement for subjective fear or expectancy ratings (no significant paths). Again, all path analyses revealed a significant impact of age on STAI-S scores (standardized path coefficient: $0.34, \mathrm{p}=0.032$ ) indicating decreased state anxiety with increasing age.

\section{DISCUSSION}

The present work provides evidence for the impact of individual differences in statedependent anxiety on the differentiability/generalization of experimentally induced ROF, which may aid our understanding of the mechanisms underlying clinical relapse.

More precisely, a negative association between state anxiety (STAI-S) and reinstatementinduced CS1/CS- (SCRs) and CS2/CS- discrimination (FPS) was observed. Importantly, the impact of state anxiety on conditioned responding was specific for the post-reinstatement test phase in SCRs while for FPS state anxiety increased reinstatement-induced responding for the CS2 specifically. Moreover, no anxiety-related differences in CS-discrimination during fear expression and extinction were observed in any dependent measure.

Taken together, our SCRs data clearly support an association between higher levels of state 
anxiety and a tendency for generalization of conditioned responding following return of fear induction. This nicely matches our previous results on the impact of recent life adversity on reinstatement-induced ROF (Scharfenort et al., 2016). This may have important clinical relevance because the ability to maintain discrimination under aversive circumstances is negatively associated with pathological anxiety (Duits et al., 2015; Lissek et al., 2005) and is predictive of resilient responding to life stress (Craske et al., 2012) while excessive generalization (i.e., failure to discriminate dangerous from safe stimuli) is a common hallmark of anxiety disorders (Duits et al., 2015; Lissek et al., 2005). In our data, state anxietydependent differences in discrimination following reinstatement in SCRs were driven by genuine differences in CS discrimination which could not be attributed to response enhancement or decrement in any CS-type specifically. Previous studies have suggested deficient safety signal processing in high and pathological anxiety (Gazendam, Kamphuis, \& Kindt, 2013; Haaker et al., 2015; Haddad, Pritchett, Lissek, \& Lau, 2012; Kong, Monje, Hirsch, \& Pollak, 2014) potentially contributing to generalized conditioned responding after adverse events (e.g. reinstatement, life events) in these individuals. Generally, our data provide evidence for state-dependent modulation of return of fear by situation-bound (state) anxiety. Our data thus may provide insight into possible mechanisms for enhanced relapse risk for affective psychopathology following exposure to major life events (Francis, Moitra, Dyck, \& Keller, 2012; Hettema, Kuhn, Prescott, \& Kendler, 2006; Kendler, Hettema, Butera, Gardner, \& Prescott, 2003) and nicely resemble the impact of recent (but not childhood) adversity on reinstatement-induced return of fear (Scharfenort et al., 2016). It can be speculated that interventions specifically tailored to target emotion regulation capacity and coping strategies to reduce negative affect in the aftermath of exposure to adversity might be efficient in reducing relapse risk in remitted patients. In fact, there is evidence that the induction of positive mood states prior to extinction learning may reduce experimentally induced return of fear (Zbozinek, Holmes, \& Craske, 2015). Future studies that 
experimentally induce positive and negative mood states prior to experimental ROF induction are warranted to investigate these hypotheses in depth to allow for causal inferences.

Our data represent an impact of state anxiety on the differentiability/generalization of cued return of fear while preliminary findings with identical directionality have been reported previously for trait anxiety (Kindt et al., 2009; Kindt \& Soeter, 2013; Scharfenort et al., 2016; Soeter \& Kindt, 2010) and for contextual cues (Glotzbach-Schoon et al., 2015). Thereby, previous results for trait anxiety were somewhat inconsistent across the studies - in particular with respect to the dependent measures and experimental groups showing this effect. It is thus conceivable that the (quality) of return of fear is mood-dependent and that effects of trait anxiety emerge due to generally rather strong correlations between measures of state and trait anxiety. Hence, as the correlation between trait and state anxiety is not linear, the moderating effects of trait anxiety may only be evident at extreme scores. In support of this hypothesis, Kindt et al. (2009) observed a correlation between trait anxiety and CS discrimination during reinstatement only in the experimental group that was characterized by significantly higher trait anxiety scores than the other experimental groups.

As ROF following reinstatement has not yet been investigated in clinical populations, studies investigating differentiability and generalization of safe and danger cues after reinstatement in patient populations and following exposure to life adversity in remitted patients are eagerly awaited. Interestingly however, while patients suffering from anxiety disorders show deficient CS discrimination already during fear acquisition and extinction (Duits et al., 2015; Lissek et al., 2005) and while trait anxiety has also been linked to deficits in CS-discrimination during conditioning and extinction (Haaker et al., 2013; Kindt \& Soeter, 2014) the effect of state anxiety was specific to reinstatement induced ROF, as previously reported for context conditioning (Glotzbach-Schoon et al., 2015). As the effect of anxiety on fear and extinction associated processes is generally rather small and hence requires large sample sizes (Haaker et al., 2015), it remains to be investigated by future larger studies whether the effect of state 
anxiety is indeed specific to ROF. Notably, however, others did neither observe an impact of (experimentally induced) state anxiety on CS discrimination during fear acquisition and extinction in a large sample (Vriends et al., 2011). Furthermore, future studies should address the impact of individual differences in state anxiety on other types of ROF such as renewal and spontaneous recovery. Thereby, similar effects can be expected (Boschen, Neumann, \& Waters, 2009).

Of note, the impact of state anxiety on reinstatement-induced conditioned responding was restricted to SCRs while reinstatement of conditioned responding in FPS, expectancy and fear ratings were not sensitive to individual differences in state anxiety. This might be explained by higher statistical power, as SCRs responses are acquired for every trial whereas verbal ratings and startle responses are only required intermittently or in $2 / 3$ of the trials respectively. Moreover, no association between STAI-S dependent discrimination scores for both outcome measures were observed in our final model. Although previous findings on the modulatory effect of anxiety levels on ROF have reported a selective impact on SCRs but not startle or US expectancy (Kindt \& Soeter, 2013) or a selective impact on startle but not SCRs or ratings of fear and US expectancy (Glotzbach, Ewald, Andreatta, Pauli, \& Mühlberger, 2012; Soeter \& Kindt, 2010) our model does not allow to infer that SCR and FPS reactivity reflect generally independent processes. Future studies need to address the impact of state anxiety on different dependent variables as well as the association between outcome measures potentially tapping into different affective processes (Hamm \& Weike, 2005; Lipp \& Purkis, 2005), in more detail.

Finally, some limitations of the present study should be discussed. First, results are limited to the effects of state anxiety and have therefore to be considered partly as hypothesisgenerating. Future studies should thus include additional measures of trait anxiety and other measures of negative affect to allow for mediation analyses. Second, future studies should extend this work by investigating the specificity of the current findings to state anxiety 
through the inclusion of other related constructs (i.e. depression, worrying). Third, the present study sample consists of healthy young individuals that present with a range in state anxiety that cannot be considered pathological (i.e. 20-44 with a possible maximum of 80 ). Hence, the generalizability of findings to populations with a larger range as well as clinical samples needs to be investigated by future studies. Finally, our experimental design consisted of three experimental stimuli and different (partly deceptive) contingency instructions. Hence, the results should be replicated by independent, less ambiguous study designs.

\subsection{CONCLUSIONS}

Here we present first evidence for state-dependent individual differences modulating the maintenance of discriminating safe from dangerous stimuli in face of adversity (i.e. experimental ROF induction through reinstatement). As such, our results from experimental return of fear may aid the understanding of mechanisms underlying clinical relapse and have potentially strong clinical implications. It can be speculated that relapse frequency might be reduced through intervention programs specifically tailored at targeting discriminating threat from safety to counteract fear generalization in particular during the aftermath of adversity in remitted patients. Furthermore, interventions to maintain or generate positive and reduce negative mood states in remitted patients may promote resilience against relapse.

\section{Acknowledgements}

This work was supported by the SFB TRR 58 subprojects B07 (to TBL) and Z02 as well as by a Young scientist grant of the University Medical Center Hamburg-Eppendorf (NWF-15/06) to TBL. The work was also funded by the Interuniversity Attraction Poles Program initiated by the Belgian Science Policy Office (IUAPVII/33) and by Ghent University Methusalem [grant number BOF09/01M00209]. The sponsors did not have any role in design and conduct of the study; collection, management, analysis, and interpretation of the data; and preparation, 
review, or approval of the manuscript.

\section{Financial Disclosures}

None of the authors reports any financial support or potential conflicts of interest.

\section{REFERENCES}

Blumenthal, T. D., Cuthbert, B. N., Filion, D. L., Hackley, S., Lipp, O. V, \& van Boxtel, A. (2005). Committee report: Guidelines for human startle eyeblink electromyographic studies. Psychophysiology, 42(1), 1-15. http://doi.org/10.1111/j.1469-8986.2005.00271.x

Boschen, M. J., Neumann, D. L., \& Waters, A. M. (2009). Relapse of successfully treated anxiety and fear: theoretical issues and recommendations for clinical practice. Australian and New Zealand Journal of Psychiatry, 43(2), 89-100. http://doi.org/10.1080/00048670802607154

Boucsein, W., Fowles, D. C., Grimnes, S., Ben-Shakhar, G., roth, W. T., Dawson, M. E., \& Filion, D. L. (2012). Publication recommendations for electrodermal measurements. Psychophysiology, 49(8), 1017-1034. http://doi.org/10.1111/j.1469-8986.2012.01384.x

Bouton, M. E. (2000). A learning theory perspective on lapse, relapse, and the maintenance of behavior change. Health Psychology: Official Journal of the Division of Health Psychology, American Psychological Association, 19(1 Suppl), 57-63.

Bouton, M. E. (2002). Context, ambiguity, and unlearning: sources of relapse after behavioral extinction. Biological Psychiatry, 3223(02).

Bouton, M. E. (2004). Context and behavioral processes in extinction. Learning \& Memory (Cold Spring Harbor, N.Y.), 11(5), 485-94. http://doi.org/10.1101/1m.78804

Bouton, M. E., \& Bolles, R. C. (1979). Role of conditioned contextual stimuli in reinstatement of extinguished fear. Journal of Experimental Psychology. Animal Behavior Processes, 5(4), 368378.

Browne, M. W., \& Cudeck, R. (1992). Alternative Ways of Assessing Model Fit. Sociological Methods \& Research, 21(2), 230-258. http://doi.org/10.1177/0049124192021002005

Craske, M. G., Wolitzky-Taylor, K. B., Mineka, S., Zinbarg, R., Waters, A. M., Vrshek-Schallhorn, 
S., ... Ornitz, E. (2012). Elevated responding to safe conditions as a specific risk factor for anxiety versus depressive disorders: evidence from a longitudinal investigation. Journal of Abnormal Psychology, 121(2), 315-324. http://doi.org/10.1037/a0025738

Duits, P., Cath, D. C., Lissek, S., Hox, J. J., Hamm, A. O., Engelhard, I. M., ... Baas, J. M. P. (2015). Updated Meta-Analysis of Classical Fear Conditioning in the Anxiety Disorders. Depression and Anxiety, 32(4), 239-53.

Fitzgerald, P. J., Seemann, J. R., \& Maren, S. (2014). Can fear extinction be enhanced? A review of pharmacological and behavioral findings. Brain Research Bulletin. http://doi.org/10.1016/j.brainresbull.2013.12.007

Francis, J. L., Moitra, E., Dyck, I., \& Keller, M. B. (2012). The impact of stressful life events on relapse of generalized anxiety disorder. Depression and Anxiety, 29(5), 386-391. http://doi.org/10.1002/da.20919

Gazendam, F. J., Kamphuis, J. H., \& Kindt, M. (2013). Deficient safety learning characterizes high trait anxious individuals. Biological Psychology, 92(2), 342-352. http://doi.org/10.1016/j.biopsycho.2012.11.006

Glotzbach, E., Ewald, H., Andreatta, M., Pauli, P., \& Mühlberger, A. (2012). Contextual fear conditioning predicts subsequent avoidance behaviour in a virtual reality environment. Cognition \& Emotion, 26(7), 1256-1272. http://doi.org/10.1080/02699931.2012.656581

Glotzbach-Schoon, E., Andreatta, M., Mühlberger, A., \& Pauli, P. (2015). Reinstatement of contextual anxiety in humans: effects of state anxiety. International Journal of Psychophysiology: Official Journal of the International Organization of Psychophysiology. http://doi.org/10.1016/j.ijpsycho.2015.07.013

Haaker, J., Gaburro, S., Sah, A., Gartmann, N., Lonsdorf, T. B., Meier, K., ... Kalisch, R. (2013). Single dose of L-dopa makes extinction memories context-independent and prevents the return of fear. Proceedings of the National Academy of Sciences of the United States of America, 110(26), E2428-36. http://doi.org/10.1073/pnas.1303061110

Haaker, J., Golkar, A., Hermans, D., \& Lonsdorf, T. B. (2014). A review on human reinstatement studies: an overview and methodological challenges. Learning \& Memory (Cold Spring Harbor, 
N.Y.), 21(9), 424-440. http://doi.org/10.1101/lm.036053.114

Haaker, J., Lonsdorf, T. B., Sch??mann, D., Menz, M., Brassen, S., Bunzeck, N., ... Kalisch, R. (2015). Deficient inhibitory processing in trait anxiety: Evidence from context-dependent fear learning, extinction recall and renewal. Biological Psychology, 111, 65-72. http://doi.org/10.1016/j.biopsycho.2015.07.010

Haddad, A. D. M., Pritchett, D., Lissek, S., \& Lau, J. Y. F. (2012). Trait Anxiety and Fear Responses to Safety Cues: Stimulus Generalization or Sensitization? Journal of Psychopathology and Behavioral Assessment, 34(3), 323-331. http://doi.org/10.1007/s10862-012-9284-7

Hamm, A. O., \& Weike, A. I. (2005). The neuropsychology of fear learning and fear regulation. International Journal of Psychophysiology : Official Journal of the International Organization of Psychophysiology, 57(1), 5-14. http://doi.org/10.1016/j.ijpsycho.2005.01.006

Hettema, J. M., Kuhn, J. W., Prescott, C. A., \& Kendler, K. S. (2006). The impact of generalized anxiety disorder and stressful life events on risk for major depressive episodes. Psychological Medicine, 36(6), 789-795. http://doi.org/10.1017/S0033291706007367

Indovina, I., Robbins, T. W., Núñez-Elizalde, A. O., Dunn, B. D., \& Bishop, S. J. (2011). Fearconditioning mechanisms associated with trait vulnerability to anxiety in humans. Neuron, 69(3), 563-71. http://doi.org/10.1016/j.neuron.2010.12.034

Kendler, K. S., Hettema, J. M., Butera, F., Gardner, C. O., \& Prescott, C. A. (2003). Life event dimensions of loss, humiliation, entrapment, and danger in the prediction of onsets of major depression and generalized anxiety. Archives of General Psychiatry, 60(8), 789-796. http://doi.org/10.1001/archpsyc.60.8.789

Kindt, M., \& Soeter, M. (2013). Reconsolidation in a human fear conditioning study: a test of extinction as updating mechanism. Biological Psychology, 92(1), 43-50. http://doi.org/10.1016/j.biopsycho.2011.09.016

Kindt, M., \& Soeter, M. (2014). Fear inhibition in high trait anxiety. PloS One, 9(1), e86462. http://doi.org/10.1371/journal.pone.0086462

Kindt, M., Soeter, M., \& Vervliet, B. (2009). Beyond extinction: erasing human fear responses and preventing the return of fear. Nature Neuroscience, 12, 256-258. http://doi.org/10.1038/nn.2271 
Kong, E., Monje, F. J., Hirsch, J., \& Pollak, D. D. (2014). Learning not to fear: neural correlates of learned safety. Neuropsychopharmacology: Official Publication of the American College of Neuropsychopharmacology, 39(3), 515-27. http://doi.org/10.1038/npp.2013.191

Lipp, O. V. (2006). Human Fear Learning: Contemporary Procedures and Measurement. In M. G. Craske, D. Hermans, \& D. Vansteenwegen (Eds.), Fear and learning: From basic processes to clinical implications (pp. 37-52). Washington, DC: American Psychological Association. http://doi.org/10.1037/11474-002

Lipp, O. V., \& Purkis, H. M. (2005). No support for dual process accounts of human affective learning in simple Pavlovian conditioning. Cognition \& Emotion, 19(2), 269-282. http://doi.org/10.1080/02699930441000319

Lissek, S., Powers, A. S., McClure, E. B., Phelps, E. a., Woldehawariat, G., Grillon, C., \& Pine, D. S. (2005). Classical fear conditioning in the anxiety disorders: A meta-analysis. Behaviour Research and Therapy, 43(11), 1391-1424. http://doi.org/10.1016/j.brat.2004.10.007

MacCallum, R. C., Browne, M. W., \& Sugawara, H. M. (1996). Power analysis and determination of sample size for covariance structure modeling. Psychological Methods, 1(2), 130-149. http://doi.org/10.1037/1082-989X.1.2.130

Mertens, G., Kuhn, M., Raes, A. K., Kalisch, R., De Houwer, J., \& Lonsdorf, T. B. (2015). Fear expression and return of fear following threat instruction with or without direct contingency experience. Cognition and Emotion, 1-17. http://doi.org/10.1080/02699931.2015.1038219

Myers, K. M., \& Davis, M. (2007). Mechanisms of fear extinction. Molecular Psychiatry, 12(2), 12050. http://doi.org/10.1038/sj.mp.4001939

Raes, A. K., De Houwer, J., De Schryver, M., Brass, M., \& Kalisch, R. (2014). Do CS-US Pairings Actually Matter? A Within-Subject Comparison of Instructed Fear Conditioning with and without Actual CS-US Pairings. PLoS ONE, 9(1), e84888. http://doi.org/10.1371/journal.pone.0084888

Rescorla, R. A., \& Heth, C. D. (1975). Reinstatement of fear to an extinguished conditioned stimulus. Journal of Experimental Psychology. Animal Behavior Processes, 1(1), 88-96.

Scharfenort, R., \& Lonsdorf, T. B. (2016). Neural correlates of and processes underlying generalized 
and differential return of fear.

Scharfenort, R., Menz, M., \& Lonsdorf, T. B. (2016). Adversity-induced relapse of fear - Neural Mechanisms and implications for relapse prevention from a study on experimentally induced return- of- fear following fear conditioning and extinction, 6(7), e858-8. http://doi.org/10.1038/tp.2016.126

Schiller, D., Monfils, M.-H., Raio, C. M., Johnson, D. C., LeDoux, J. E., \& Phelps, E. A. (2010). Preventing the return of fear in humans using reconsolidation update mechanisms. Nature, 463, 49-53. http://doi.org/10.1038/nature08637

Soeter, M., \& Kindt, M. (2010). Dissociating response systems: Erasing fear from memory. Neurobiology of Learning and Memory, 94(1), 30-41. http://doi.org/10.1016/j.nlm.2010.03.004

Spielberger, C. D., Gorsuch, R. L., Lushene, P. R., Vagg, P. R., \& Jacobs, A. G. (1983). Manual for the State-Trait Anxiety Inventory (Form Y). Manual for the statetrait anxiety inventory STAI.

Vervliet, B., Craske, M. G., \& Hermans, D. (2013). Fear extinction and relapse: state of the art. Annual Review of Clinical Psychology, 9, 215-48. http://doi.org/10.1146/annurev-clinpsy$050212-185542$

Vriends, N., Michael, T., Blechert, J., Meyer, A. H., Margraf, J., \& Wilhelm, F. H. (2011). The influence of state anxiety on the acquisition and extinction of fear. Journal of Behavior Therapy and Experimental Psychiatry, 42(1), 46-53. http://doi.org/10.1016/j.jbtep.2010.09.001

Wittchen, H. U., Jacobi, F., Rehm, J., Gustavsson, a, Svensson, M., Jönsson, B., ... Steinhausen, H.C. (2011). The size and burden of mental disorders and other disorders of the brain in Europe 2010. European Neuropsychopharmacology: The Journal of the European College of Neuropsychopharmacology, 21(9), 655-79. http://doi.org/10.1016/j.euroneuro.2011.07.018

Yonkers, K. A., Bruce, S. E., Dyck, I. R., \& Keller, M. B. (2003). Chronicity, relapse, and illness-course of panic disorder, social phobia, and generalized anxiety disorder: findings in men and women from 8 years of follow-up. Depression and Anxiety, 17(3), 173-179. http://doi.org/10.1002/da.10106

Zbozinek, T. D., Holmes, E. A., \& Craske, M. G. (2015). The effect of positive mood induction on reducing reinstatement fear: Relevance for long term outcomes of exposure therapy. Behaviour 
Research and Therapy, 71, 65-75. http://doi.org/10.1016/j.brat.2015.05.016 